\title{
Determining Heavy Metal (loid) Stabilization Materials and Optimum Mixing Ratio: Aqueous Batch test
}

\author{
Seung Min Oh, Se Jin Oh, Sung Chul Kim¹, Sang Hwan Lee², Yong Sik Ok, and Jae E. Yang* \\ Department of Biological Environment, Kangwon National University, Chuncheon 200-701, Korea \\ ${ }^{1}$ Department of Bioenvironmental Chemistry, Chungnam National University, Daejeon 305-764, Korea \\ ${ }^{2}$ Institute of Mine Reclamation Technology, Korea Mine Reclamation Corporation, Cheonan 331-803, Korea
}

(Received: November 20 2014, Revised: December 24 2014, Accepted: December 24 2014)

Acid mine drainage sludge (AMDS) has been classified as mine waste and generally deposited in land. For this reason, studies have been conducted to examine the possibility of recycling AMDS as an amendment for heavy metal stabilization in soil. The main objective of this study was to evaluate heavy metal stabilization efficiency of AMDS comparing with the widely used lime stone. Also, optimum mixing ratio was evaluated for enhancing heavy metal stabilization. AMDS and limestone were mixed at the ratio of 0:100, 25:75, 50:50,

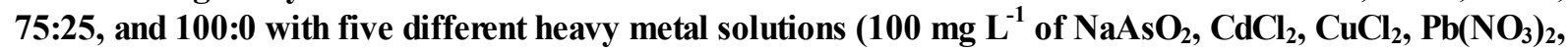
and $\left.\mathrm{ZnSO}_{4} \cdot 7 \mathrm{H}_{2} \mathrm{O}\right)$. The amendments were added at a rate of $3 \%(\mathrm{w} / \mathrm{v})$. In order to determine the stabilization kinetics, samples were collected at different reaction time of $0,1,2,4,8,16,32,64,128,256,512,1024$ minutes. The heavy metal stabilization by AMDS was faster and higher than those of limestone for all examined heavy metals. While limestone showed only $20 \%$ of arsenic (As) stabilization after 1,024 minutes, $96 \%$ of As was stabilized within 1 minute by AMDS. The highest effect on the stabilization of heavy metal (loid) was observed, when the two amendments were mixed at a ratio of 1:1. These results indicated that AMDS can be effectively used for heavy metal stabilization in soil, especially for As, and the optimum mixing ratio of AMDS and lime was 1:1 at a rate of $3 \%(w / v)$.

Key words: Amendment, Arsenic, Heavy metal, Kinetics, Stabilization

Rate constants $(k)$ and half-life time $\left(t_{1 / 2}\right)$ of first order kinetics for different mixing ratios of two amendments.

\begin{tabular}{|c|c|c|c|}
\hline Treatment & Elements & Rate constants $(\mathrm{k})$ & Half-life time $\left(\mathrm{t}_{1 / 2}, \min .\right)$ \\
\hline $\begin{array}{c}\text { LS:AMDS } \\
0: 100\end{array}$ & $\begin{array}{l}\mathrm{As} \\
\mathrm{Cd} \\
\mathrm{Cu} \\
\mathrm{Pb} \\
\mathrm{Zn}\end{array}$ & $\begin{array}{l}1.7062 \\
0.6407 \\
0.9747 \\
2.8407 \\
0.5340\end{array}$ & $\begin{array}{r}0.41 \\
1.08 \\
0.71 \\
0.24 \\
1.30\end{array}$ \\
\hline $\begin{array}{c}\text { LS:AMDS } \\
25: 75\end{array}$ & $\begin{array}{l}\mathrm{As} \\
\mathrm{Cd} \\
\mathrm{Cu} \\
\mathrm{Pb} \\
\mathrm{Zn}\end{array}$ & $\begin{array}{l}1.3892 \\
0.8220 \\
2.0930 \\
3.9024 \\
0.9875\end{array}$ & $\begin{array}{l}0.50 \\
0.84 \\
0.33 \\
0.18 \\
0.70\end{array}$ \\
\hline $\begin{array}{c}\text { LS:AMDS } \\
50: 50\end{array}$ & $\begin{array}{l}\mathrm{As} \\
\mathrm{Cd} \\
\mathrm{Cu} \\
\mathrm{Pb} \\
\mathrm{Zn}\end{array}$ & $\begin{array}{l}1.0781 \\
0.8950 \\
2.1142 \\
3.6818 \\
1.2684\end{array}$ & $\begin{array}{l}0.64 \\
0.77 \\
0.33 \\
0.19 \\
0.55\end{array}$ \\
\hline $\begin{array}{c}\text { LS:AMDS } \\
75: 25\end{array}$ & $\begin{array}{l}\mathrm{As} \\
\mathrm{Cd} \\
\mathrm{Cu} \\
\mathrm{Pb} \\
\mathrm{Zn}\end{array}$ & $\begin{array}{l}0.6074 \\
0.4861 \\
1.9943 \\
2.5243 \\
1.1331\end{array}$ & $\begin{array}{l}1.14 \\
1.43 \\
0.35 \\
0.27 \\
0.61\end{array}$ \\
\hline $\begin{array}{c}\text { LS:AMDS } \\
100: 0\end{array}$ & $\begin{array}{l}\mathrm{As} \\
\mathrm{Cd} \\
\mathrm{Cu} \\
\mathrm{Pb} \\
\mathrm{Zn}\end{array}$ & $\begin{array}{l}0.0006 \\
0.0004 \\
0.4523 \\
2.5642 \\
0.5337\end{array}$ & $\begin{array}{c}1155.00 \\
1732.50 \\
1.53 \\
0.27 \\
1.30\end{array}$ \\
\hline
\end{tabular}

*Corresponding author : Phone: +82332506446, Fax: +82332416640, E-mail: yangjay@kangwon.ac.kr

${ }^{\S}$ Acknowledgement: This project was supported by "Optimum Remediation Technology for Heavy Metal Stabilization and Soil Amelioration" through the Mine Reclamation Corporation (MIRECO). The instrumental analysis was partly supported by the Central Laboratory of Kangwon National University, in Korea. 


\section{Introduction}

중금속 (heavy metal)은 난분해성 물질로써 고농도로 환 경에 축적될 경우 동식물의 생장을 저해하며, 또한 중금속 으로 오염된 물과 작물을 인간이 장기간 섭취하면 중금속이 인간 체내에 축적되어 악영향을 초래한다. 특히, 농경지 중 금속 오염은 작물전이와 수계유입 등을 통하여 인체중독의 원인이 되며, 대부분의 중금속 오염 농경지는 휴폐광산 주 변에서 나타나고 있다 (Nan et al., 2002; Cui et al., 2004; Lee et al., 2012). 최근에는 휴폐광산 인근 농경지에서 재 배되는 농산물 중 중금속 기준치를 초과하는 사례가 발생하 여 농림수산식품부와 지방자치단체가 해당지역 농산물을 폐기하는 절차를 진행하기도 하였다. 이러한 중금속 오염 농경지의 복원기술로는 객/복토 (soil addition/covering), 토양세척 (soil washing), 전기동력학적기법 (electrokinetics), 식물정화법 (phytoremediation) 등의 처리기술과 석회, 유 기물질, 철/망간 산화물과 같은 안정화제를 이용하여 불용 화 하는 기술이 있다 (Ahn, 2000). 이중 안정화 기술은 주 입한 안정화제가 중금속을 흡착 (adsorption) 또는 공침 (coprecipitation) 시켜 중금속의 이동성과 독성 감소 및 식물 전이를 저감하는 방법이다 (Kumpiene et al., 2008). 안정 화 기술은 상대적으로 저렴한 비용, 처리기간과 복원 효율 의 발현 기간이 비교적 짧기 때문에 우리나라 휴폐광산 주 변에 위치한 중금속 오염농경지를 처리하기 위해 선택할 수 있는 매우 유용한 방법으로 인식되고 있다 (Lee, 2007). 안 정화에 사용되는 물질로는 석회석, 소석회, 석탄회 등과 같 은 알칼리 재료와 철산화물, 알루미늄산화물 그리고 망간산 화물과 같은 금속산화물 및 점토, 인산염, 퇴비 등의 다양한 무기물과 유기물 등이 적용될 수 있다 (Kumpiene et al., 2008; Janos et al., 2010; Jeon et al., 2010). 하지만, 이러 한 안정화 물질 중 현재 석회와 제강슬래그 등이 제한적으 로 현장에 적용되고, 대부분의 물질이 효율성 검증 단계에 머물러 있다. 선행 연구사례에서 몇몇 안정화제들에 대한 평 가는 이루어 졌지만, 대부분의 안정화제들에 대하여는 가능 성 제시 및 목록만 작성되어있을 뿐 종합적인 평가는 이루 어지지 않은 실정이다 (Kim, 2010). 또한 폐금속 광산에서 는 과거 채광, 선광 및 제련 등의 광산활동으로 인해 배출된 광산 폐기물이 주변에 그대로 방치되고 광산배수는 제대로 처리되지 않아 광산주변 농경지와 수계를 오염시키는 사례 가 빈번히 발생하였으며 최근 들어 광산배수의 처리기술이 발달하게 되었다. 특히 산성광산배수 처리는 중화처리 및 $\mathrm{Fe}, \mathrm{Al}, \mathrm{Mn}$ 등의 이온을 제거하기 위하여 소석회 $\left(\mathrm{Ca}(\mathrm{OH})_{2}\right)$, 가성소다 $(\mathrm{NaOH})$, 응집제 등을 이용하여 처리하게 된다 (Maree et al., 2004; An et al., 2010). 이러한 처리과정에서 다량 의 $\mathrm{Fe}$ 을 함유한 슬러지가 발생하게 되는데 발생한 슬러지의 대부분은 매립에 의해 처리되고 있으며, 슬러지의 매립은
중금속의 잠재적 오염원을 조성하게 된다. 따라서 지속가능 한 광해복구를 위해서는 광산배수 처리시설에서 발생되는 슬러지의 재활용 방안이 반드시 필요하며, 최근에는 $\mathrm{AMD}$ 슬러지의 As 제거 효율이 뛰어나 As 안정화제로서의 재활 용가능성을 보여주는 결과가 확인된 바 있다 (Ko et al., 2010). 그러므로 본 연구에서는 중금속 안정화에 가장 널리 사용되는 석회물질과 재활용방안 마련이 시급한 $\mathrm{AMD}$ 슬러 지를 이용하여 수용액 내 비소 및 중금속 제거 효율을 확인 함으로써 효율적인 중금속 안정화기술에 적용하고자 수행 하였다.

\section{Materials and Methods}

안정화제 특성 분석 본 연구에서 수용액 내 중금속 제 거에 사용된 석회석 (DAESUNG MDI, Jaecheon)과 $\mathrm{AMD}$ 슬 러지 (Hamtae Coal Mine, Taebaek)의 화학적 특성 분석은 국립농업과학원의 토양 및 식물체 분석법 (NAAS, 2000)에 준하여 실험하였다. 안정화제의 화학적 특성 중 $\mathrm{pH}(1: 5)$ 와 전기전도도 (EC, Electric Conductivity, 1:5)는 건조한 안정 화제 $10 \mathrm{~g}$ 에 증류수 $50 \mathrm{~mL}$ 을 첨가하여 30 분간 진탕 후 Whatman No. 2로 여과시킨 후 pH meter (FE 20, MettlerToledo)와 EC meter (FE 30, Mettler-Toledo)를 이용하여 각각 측정하였다. 유효인산 $\left(\mathrm{P}_{2} \mathrm{O}_{5}\right)$ 함량은 Bray No.1 방법과 염화주석 $\left(\mathrm{SnCl}_{2}\right)$ 환원법을 사용하여 ammonium paramolybdate 로 발색시켜 파장 $660 \mathrm{~nm}$ 에서 UV/Visible Spectrophotometer (UV 240 Shimadzu, Japan)를 이용하여 비색 정량하였으 며, 양이온교환용량 (cation exchange capacity, CEC)은 1 $\mathrm{N}$ Acetic acid ( $\mathrm{pH}$ 2.31)법으로 측정하였다 (Kim et al., 2012b). 안정화제의 중금속 함량은 토양오염공정시험기준 (ME, 2012)의 왕수 추출을 이용한 중금속 전 함량 분석과 한국폐기물용출실험법 (Korea Leaching Test) 및 미국 EPA 의 TCLP (Toxicity Characteristic Leaching Procedure, EPA method 1311)방법에 준하였으며, 기기분석은 유도결합플라 즈마분광광도계 (Inductively Coupled Plasma - Optical Emission Spectrophotometer, Thermo, iCAP 6000 series) 를 이용하여 중금속을 정량 분석하였다.

중금속 수용액 제조 Batch experiment에 사용된 중금 속 수용액의 제조는 $\mathrm{As}\left(\mathrm{NaAsO}_{2}, 96 \%\right), \mathrm{Cd}\left(\mathrm{CdCl}_{2}, 99 \%\right)$, $\mathrm{Cu}\left(\mathrm{CuCl}_{2}, 97 \%\right), \mathrm{Pb}\left(\mathrm{Pb}\left(\mathrm{NO}_{3}\right)_{2}, 99 \%\right)$ 및 $\mathrm{Zn}\left(\mathrm{ZnSO}_{4} \cdot 7 \mathrm{H}_{2} \mathrm{O}\right.$, $99.5 \%$ )가 각각 $100 \mathrm{mg} / \mathrm{L}$ 가 되도록 조제하였다 (Kim, 2010).

수용액 내 중금속 제거 Batch 실험 $100 \mathrm{mg} / \mathrm{L}$ 로 제 조된 중금속 수용액과 안정화제의 투입비율을 $3 \%(\mathrm{w} / \mathrm{v})$ 로 설정 하여 진행하였으며, 안정화제의 혼합 비율은 석회석 (LS):AMD 슬러지 (AMDS)를 0:100, 25:75, 50:50, 75:25, 100:0의 혼 
합비율로 투입하였다. 안정화제와 중금속 수용액의 반응시 간은 $25^{\circ} \mathrm{C}$ 에서 $1,2,4,8,16,32,64,128,256,512,1024$ $\min$. 동안 반응 시켰으며, 반응 후 Whatman No. 42 로 여과 하고 여액을 ICP-OES (Thermo, iCAP 6000 series)를 이용 하여 중금속을 측정함으로써 석회석과 $\mathrm{AMD}$ 슬러지의 혼합 비율에 따른 중금속 제거효율을 비교하였다.

반응속도상수 $(\mathrm{k})$ 와 반감기 $\left(\mathrm{t}_{1 / 2}\right)$ 산출 반응시간에 따른 수용액 내 중금속의 농도 결과를 이용하여 반응속도상 수 $(\mathrm{K})$ 와 반감기 $\left(\mathrm{t}_{1 / 2}\right)$ 를 산출하였다 (Yang et al., 1995). 반 응속도상수와 반감기는 first order kinetic model에 적용하 여 안정화제 혼합비율에 따른 중금속 $\mathrm{As}, \mathrm{Cd}, \mathrm{Cu}, \mathrm{Pb}$ 및 $\mathrm{Zn}$ 에 대한 각각의 반응속도상수와 반감기를 산출하였다 $(\mathrm{Eq}$. 1: 반응속도, Eq. 2: 반감기).

$$
\begin{aligned}
& C_{t}=C_{0} e^{-k t} \rightarrow e^{-k t}=\frac{C_{t}}{C_{0}} \rightarrow \ln \frac{C_{t}}{C_{0}}=-k t \\
& \ln \frac{0.5 C_{0}}{C_{0}}=-k t_{1 / 2} \rightarrow 0.693=-k t_{1 / 2} \rightarrow t_{1 / 2}=\frac{0.693}{k}
\end{aligned}
$$

$[\mathrm{C}]_{0}$ : Initial concentration

$[C]_{t}$ : Concentration of $t$ hour after

$\mathrm{k}$ : rate constants

$\mathrm{t}:$ reaction time

\section{Results and Discussion}

안정화제의 화학적 특성 분석결과 안정화제의 화학 적 특성 분석 결과를 Table 1에 나타내었다. 석회석과 $\mathrm{AMD}$ 슬러지 $\mathrm{pH}$ 는 각 9.1과 8.4로 알칼리적 특성을 띄고 있었으 며, $\mathrm{EC}$ 는 석회석에서 $0.07 \mathrm{dS} / \mathrm{m}, \mathrm{AMD}$ 슬러지에서 $0.76 \mathrm{dS} / \mathrm{m}$ 로 석회석보다 $\mathrm{AMD}$ 슬러지에서 약 10 배정도 높게 나타났지 만, 농경지 토양에 적용하거나 식물체에 큰 영향을 주는 수 준은 아닌 것으로 확인되었다 (Kim et al., 2012a). 유기물 의 함량은 $\mathrm{AMD}$ 슬러지에서 $15.52 \mathrm{~g} / \mathrm{kg}$ 수준으로 일반적인 토양의 적정 수준인 20 30 g/kg (Yang and Lee, 2001)과 비교해보았을 때 크게 높지는 않은 것으로 나타났다. 유효 인산의 경우 석회석에서 $13.38 \mathrm{mg} / \mathrm{kg}$ 과 $\mathrm{AMD}$ 슬러지에서는

Table 1. Chemical properties of two amendments.

\begin{tabular}{ccccc}
\hline \hline Amendment & $\mathrm{pH}$ & $\mathrm{EC}$ & $\mathrm{OM}^{\dagger}$ & $\mathrm{P}_{2} \mathrm{O}_{5}^{\ddagger}$ \\
\hline & $(1: 5)$ & $\mathrm{dS} / \mathrm{m}$ & $\mathrm{g} / \mathrm{kg}$ & $\mathrm{mg} / \mathrm{kg}$ \\
Limestone & 9.1 & 0.07 & 9.52 & 13.38 \\
AMD sludge & 8.4 & 0.76 & 15.52 & $\mathrm{ND}^{\Uparrow}$ \\
\hline
\end{tabular}

"Organic matter, ${ }^{*}$ Available phosphorous, ${ }^{\text {TNot detected }}$
검출한계 이하의 값으로 검출되어 두 안정화제 모두 유효인 산의 함량은 낮게 검출되었다.

\section{안정화제의 중금속 함량 석회석의 경우 토양오염공} 정시험기준 $(\mathrm{ME}, 2012)$ 으로 중금속 전함량 분석한 결과 $\mathrm{As}$ 와 $\mathrm{Cd}$ 은 검출되지 않았으며 $\mathrm{Cu}, \mathrm{Pb}$ 그리고 $\mathrm{Zn}$ 의 중금속 함 량 또한 각 $0.41,1.59,7.45 \mathrm{mg} \mathrm{kg}^{-1}$ 으로 토양환경보전법의 우려기준에 크게 못 미치는 것으로 보아 중금속 안정화 물 질로 사용하는데 큰 어려움이 없을 것으로 판단되었다 $(\mathrm{ME}$, 2013). 전 함량 분석 외 한국폐기물용출시험 (Korean leaching test, KLT)과 EPA method 1311 (Toxicity characteristic leaching procedure, TCLP)를 이용한 석회석의 중금속 용출 을 확인한 결과 한국폐기물용출시험으로 용출한 경우 석회 석에서는 $\mathrm{As}, \mathrm{Cd}, \mathrm{Cu}, \mathrm{Pb}$ 및 $\mathrm{Zn}$ 모두 검출 되지 않았으며, $\mathrm{EPA}$ 의 폐기물용출시험법으로 용출한 경우 $\mathrm{Pb}$ 와 $\mathrm{Zn}$ 이 검출 되었지만 각 $0.03 \mathrm{mg} / \mathrm{L}$ 수준으로 매우 미량 용출됨을 확인 하였다.

$\mathrm{AMD}$ 슬러지의 중금속을 토양오염공정시험기준으로 전함 량을 분석한 결과 $\mathrm{As}$ 와 $\mathrm{Cu}$ 는 검출되지 않았으며, $\mathrm{Pb}$ 은 $6.30 \mathrm{mg} / \mathrm{kg}$ 으로 기준치보다 매우 낮게 검출되었다 (토양오 염 우려기준: $\mathrm{As}-25 \mathrm{mg} / \mathrm{kg}, \mathrm{Cd}-4 \mathrm{mg} / \mathrm{kg}, \mathrm{Cu}-50 \mathrm{mg} / \mathrm{kg}$, $\mathrm{Pb}-200 \mathrm{mg} / \mathrm{kg}, \mathrm{Zn}-300 \mathrm{mg} / \mathrm{kg} ; \mathrm{ME}, 2013)$. 그러나 Cd과 $\mathrm{Zn}$ 의 경우는 각 $29.84 \mathrm{mg} / \mathrm{kg}$ 과 $996.46 \mathrm{mg} / \mathrm{kg}$ 으로 토양오 염공정시험기준 중 대책기준을 초과하는 수준으로 검출되 었다 (토양오염 대책기준: $\mathrm{As}-75 \mathrm{mg} / \mathrm{kg}, \mathrm{Cd}-12 \mathrm{mg} / \mathrm{kg}, \mathrm{Cu}-$ $150 \mathrm{mg} / \mathrm{kg}, \mathrm{Pb}-600 \mathrm{mg} / \mathrm{kg}, \mathrm{Zn}-900 \mathrm{mg} / \mathrm{kg} ; \mathrm{ME}, 2013)$. 반면, 한국폐기물용출시험법에서는 $0.01 \mathrm{mg} / \mathrm{kg}$ 의 $\mathrm{Pb}$ 이외 의 원소는 검출되지 않았으며, $\mathrm{EPA}$ 의 폐기물용출시험법도 $\mathrm{Pb} 0.04 \mathrm{mg} / \mathrm{kg}$ 과 Zn $4.90 \mathrm{mg} / \mathrm{kg}$ 외에는 중금속이 검출되 지 않았다. Table 2 의 결과로 미루어 볼 때 석회석의 경우 함유 중금속과 용출 중금속의 함량 자체가 미량으로 확인되 었으므로 중금속 안정화제로의 사용이 크게 문제가 되지 않 을 것으로 판단된다. $\mathrm{AMD}$ 슬러지의 경우 전함량 분석결과 $\mathrm{Cd}$ 과 $\mathrm{Zn}$ 의 함유량이 많음이 확인되었지만, 약 산성용액을 사용한 한국폐기물용출시험과 EPA의 폐기물용출시험 결과 에서 중금속의 용출이 크게 나타나지 않아 안정화제로의 효 율성을 판단할 필요성이 있었다. 폐기물용출시험방법은 중 금속 유출 우려가 있는 물질이 산성우에 노출되거나 매립지 의 환경에서 중금속의 유출을 감안한 시험방법으로 실제 환 경에서 용출되는 중금속을 예측할 수 있는 방법이다 (Eo, 1994). 그러므로 $\mathrm{AMD}$ 슬러지의 $\mathrm{Cd}, \mathrm{Zn}$ 의 전함량이 높게 나 타났지만, 폐기물용출시험법을 통해 용출이 확인되지 않고, 중금속 안정화 능력이 확인 된다면 안정화제로의 사용이 가 능할 것으로 판단된다. 또한 안정화제의 사용으로 인한 중 금속 유입은 실제적으로 하수 또는 토양에 처리되는 단위가 $3 \sim 5 \%$ 정도의 수준이기 때문에 실제적인 전함량 변화 미치 
Table 2. Heavy metal concentration of two amendments.

\begin{tabular}{|c|c|c|c|c|c|c|c|c|c|c|c|c|c|c|c|}
\hline \multirow{2}{*}{ Amendment } & \multicolumn{5}{|c|}{ Aqua regia } & \multicolumn{5}{|c|}{$\mathrm{KLT}^{\dagger}$} & \multicolumn{5}{|c|}{ TCLP $^{\ddagger}$} \\
\hline & As & $\mathrm{Cd}$ & $\mathrm{Cu}$ & $\mathrm{Pb}$ & $\mathrm{Zn}$ & As & $\mathrm{Cd}$ & $\mathrm{Cu}$ & $\mathrm{Pb}$ & $\mathrm{Zn}$ & As & $\mathrm{Cd}$ & $\mathrm{Cu}$ & $\mathrm{Pb}$ & $\mathrm{Zn}$ \\
\hline & ------ & - & $\mathrm{mg} / \mathrm{kg}$ & ----- & 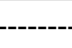 & ---- & ----- & 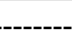 & ------ & $---m$ & L --- & 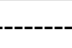 & ----- & ----- & ----- \\
\hline Limestone & $\mathrm{ND}^{q}$ & ND & 0.41 & 1.89 & 7.48 & ND & ND & ND & ND & ND & ND & ND & ND & 0.03 & 0.03 \\
\hline AMD sludge & ND & 29.8 & ND & 6.30 & 966 & ND & ND & ND & 0.01 & ND & ND & 0.01 & ND & 0.04 & 4.90 \\
\hline
\end{tabular}

${ }^{\dagger}$ Korean leaching test, ${ }^{\ddagger}$ Toxicity characteristic leaching procedure, ${ }^{~}$ Not detected

는 영향은 적을 것으로 판단된다.

수용액 내 중금속 제거 각 중금속 원소 $(\mathrm{As}, \mathrm{Cd}, \mathrm{Cu}$, $\mathrm{Pb}$ 및 $\mathrm{Zn})$ 에 대하여 석회석과 $\mathrm{AMD}$ 슬러지의 혼합비율 (0:100, $25: 75,50: 50,75: 25,100: 0)$ 을 다르게 하여 수용액 내 중금 속 제거효율을 확인하였다. 초기부터 $1024 \mathrm{~min}$. 까지 수용 액 내 중금속 제거 효율을 확인한 결과 석회석을 단일 처리 하였을 경우 $\mathrm{Pb}$ 에 대하여는 $1 \mathrm{~min}$. 경과 후부터 높은 $99 \%$ 정도의 효율이 나타났으며, $\mathrm{Cd}$ 은 $1024 \mathrm{~min}$. 경과 후 약 $50 \%, \mathrm{Cu}$ 는 $1024 \mathrm{~min}$. 경과 후 약 $70 \%, \mathrm{Zn}$ 은 80\%의 제거 효 율을 나타냈다. 반면, $\mathrm{As}$ 의 경우 석회석만 처리되었을 때 $1024 \mathrm{~min}$. 경과 후에도 약 20\%의 제거효율 수준인 것으로 나타났다. $\mathrm{As}$ 의 안정화는 $\mathrm{AMD}$ 슬러지의 혼합비율이 높아질 수록 그 효율이 증가하는 것으로 나타났다. 또한 $\mathrm{AMD}$ 슬러 지 단일 처리구에서 석회석 단일 처리구 보다 모든 금속 원 소에 대하여 더 높은 효율을 보였다. 석회석 단일 처리의 경 우 석회석에서 방출되는 carbonate $\left(\mathrm{CO}_{3}{ }^{2-}\right)$, hydroxide $\left(\mathrm{OH}^{-}\right)$ 등에 의한 $\mathrm{pH}$ 상승효과로 침전물이 형성되어 $\mathrm{Cd}, \mathrm{Cu}, \mathrm{Pb}$ 및 $\mathrm{Zn}$ 의 불용화가 나타난 것으로 판단되며 $(\mathrm{Kim}, 2010 ; \mathrm{Oh}$ et al., 2011a, 2011b; Eq. 3, 4), As 안정화의 경우 시간이 경과함에 따라 석회석이 함유한 $\mathrm{Ca}^{2+}$ 과 $\mathrm{As}$ 가 $\mathrm{Ca}-\mathrm{As}$ 의 결합 을 형성하여 $1024 \mathrm{~min}$. 이후 $20 \%$ 의 제거 효율을 나타낸 것 으로 판단된다 (Ahn et al., 2003; Moon et al., 2010). 석회 석의 $\mathrm{As}$ 안정화 주요 기작은 $\mathrm{pH}$ 의 상승에 의한 침전물 형성 보다는 $\mathrm{Ca}-\mathrm{As}$ 형태의 불용성 침전과 금속산화물에 대한 흡 착으로 인한 안정화가 주로 보고되고 있다 (Moon et al., $2004,2008,2010) . \mathrm{Ca}-\mathrm{As}$ 의 불용성 침전형태는 다음과 같 다 (Ahn et al., 2003; Eq. 5, 6, 7).

$$
\begin{gathered}
\mathrm{M}^{2+}+\mathrm{OH} \rightarrow \mathrm{M}(\mathrm{OH})_{2(S)} \\
\mathrm{M}^{2+}+\mathrm{CO}_{3}^{2-} \rightarrow \mathrm{MCO}_{3(S)}
\end{gathered}
$$

(M: metal)

$$
\begin{aligned}
& \mathrm{HAsO}_{4}^{2-}+\mathrm{Ca}^{2+}+n \mathrm{H}_{2} \mathrm{O} \rightarrow \mathrm{CaHAsO}_{4} \cdot n \mathrm{H}_{2} \mathrm{O} \\
& 2 \mathrm{AsO}_{3}^{3-}+2 \mathrm{Ca}^{2+}+n \mathrm{H}_{2} \mathrm{O} \rightarrow \mathrm{Ca}_{3}\left(\mathrm{AsO}_{4}\right)_{2} \cdot n \mathrm{H}_{2} \mathrm{O}
\end{aligned}
$$

$$
\mathrm{HAsO}_{3}^{2-}+\mathrm{Ca}^{2+}+\mathrm{nH}_{2} \mathrm{O} \rightarrow \mathrm{CaHAsO}_{3} \cdot \mathrm{nH}_{2} \mathrm{O}
$$

$\mathrm{AMD}$ 슬러지는 $\mathrm{AMD}$ 를 처리하기 위하여 알칼리 중화제로 $\mathrm{NaOH}, \mathrm{Ca}(\mathrm{OH})_{2}, \mathrm{CaCO}_{3}$ 를 첨가하고 이에 따라 침전된 슬러 지를 말한다 (Oh and Park, 2005). 따라서 $\mathrm{AMD}$ 슬러지 내 에는 $\mathrm{Ca}$ base의 물질이 다량 함유되어 있으며 (15\%; Oh et al., 2011a, 2011b), 침전물 내에는 그 외 산화철, 산화마그 네슘 등 산화금속광물의 함량도 높게 나타난다 (59\%; Oh et al., 2011a, 2011b; Song et al., 2012). 앞에서 설명한 바와 같이 $\mathrm{As}$ 는 $\mathrm{pH}$ 에 의한 안정화 보다 $\mathrm{Ca}-\mathrm{As}$ 결합에 의한 안정 화가 우세하고, 또한 금속산화물 흡착을 통해서도 높은 As 제거 효율을 보여준다. 이 중에서도 영가철 (zero valent iron, ZVI)과 철 수산화물 (iron hydroxide)을 이용한 비소 흡착 방법이 비소제거 효과가 가장 뛰어난 것으로 입증된 선행연구가 있다 (Fuller et al., 1993; Wilkie and Hering, 1996; Raven et al., 1998; Dixit et al., 2003; Masue et al., 2007; Jung et al., 2008). Ferrous hydroxide, ferric hydroxide 는 철 수산화물로서 $\mathrm{As}$ 와 결합하여 불용성의 $\mathrm{FeAsO}_{4} \cdot \mathrm{nH}_{2} \mathrm{O}$ (amorphous scorodite)를 형성하여 As의 용출을 감소시킨 다 (Lim et al., 2010). 따라서 $\mathrm{AMD}$ 슬러지 내의 높은 $\mathrm{Ca}$ 와 $\mathrm{Fe}$ 함량이 수용액 내 $\mathrm{As}$ 의 제거에 크게 기여한 것으로 판단 되며, 본 연구에서 석회석 단일 처리와 $\mathrm{AMD}$ 슬러지 단일 처 리를 한 처리구의 결과로 미루어 볼 때 $\mathrm{Ca}-\mathrm{As}$ 형성에 의한 $\mathrm{As}$ 의 제거 효율보다 철수산화물 흡착에 의한 $\mathrm{As}$ 의 제거효 율이 더 우세한 것으로 판단된다 $\left(\mathrm{Fe}_{2} \mathrm{O}_{3}: 56 \%\right)$. 그리고 혼합 비율에 따른 $\mathrm{As}$ 및 중금속에 대한 종합적인 제거 최적 혼합 비율은 $\mathrm{AMD}$ 슬러지를 단일로 처리했을 경우 보다 석회석을 혼합한 처리구에서 $\mathrm{Cd}, \mathrm{Cu}, \mathrm{Zn}$ 에 대한 제거 효율이 더욱 증 가하였으며, 석회석의 혼합비율이 $\mathrm{AMD}$ 슬러지보다 높아지 게 되면 상대적으로 $\mathrm{As}$ 의 제거효율이 감소하였다. 석회석과 $\mathrm{AMD}$ 슬러지를 50:50으로 혼합한 처리구에서 각 시간대별로 혼합비율 중 가장 좋은 제거 효율을 확인하였다.

반응속도 상수 $(k)$ 와 반감기 $\left(\mathbf{t}_{1 / 2}\right)$ 산출 반응속도상 수 $(\mathrm{k})$ 는 반응력이라고 할 수 있으며, 일반적으로 반응속도 상수가 클수록 반응이 빠르고 급격히 일어남을 뜻한다. 반 감기 $\left(\mathrm{t}_{1 / 2}\right)$ 는 원 물질의 농도가 처음농도의 반으로 감소되기 까지의 시간을 뜻하며, 반응력이 클수록 반감기는 작아지게 


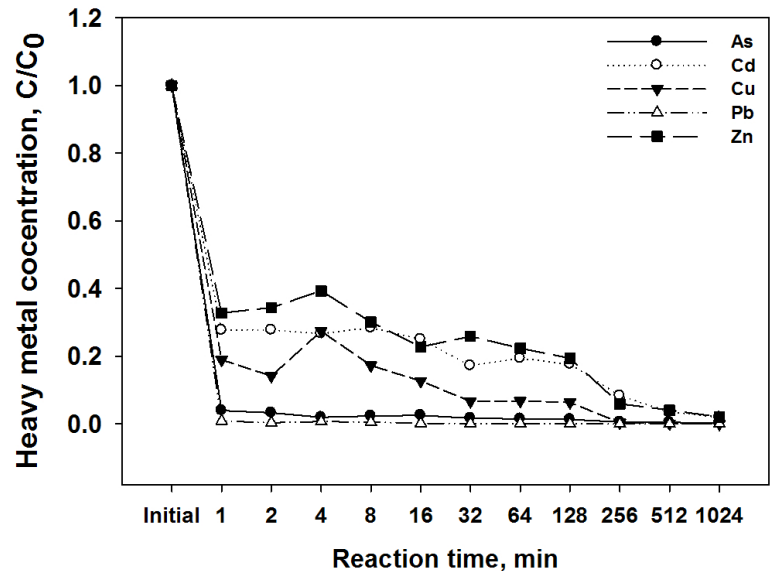

(a) LS:AMDS, 0:100

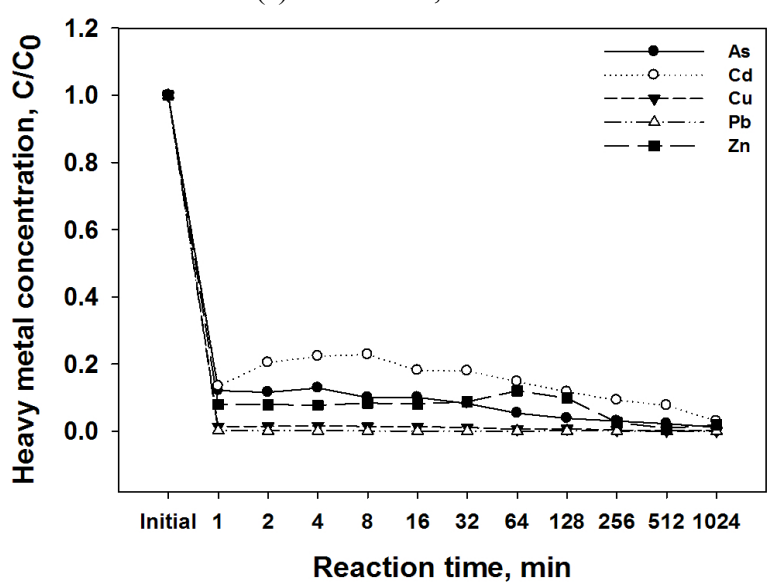

(c) LS:AMDS, 50:50

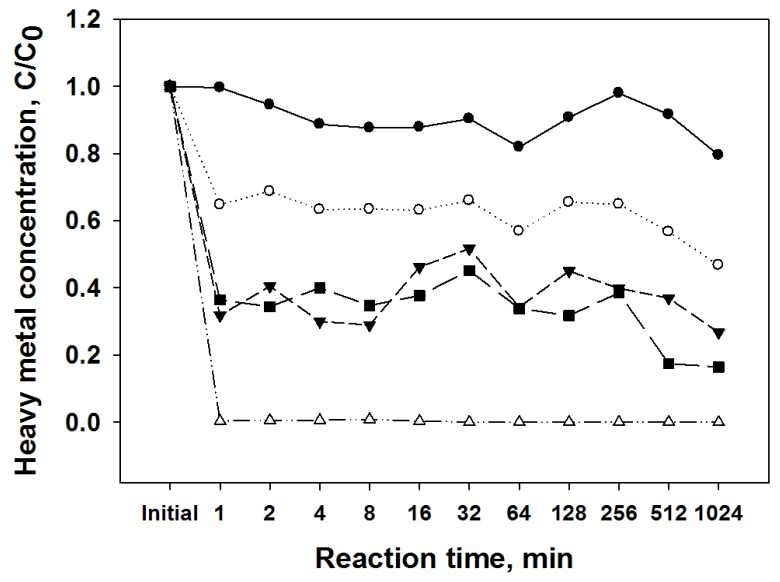

(e) LS:AMDS, 100:0

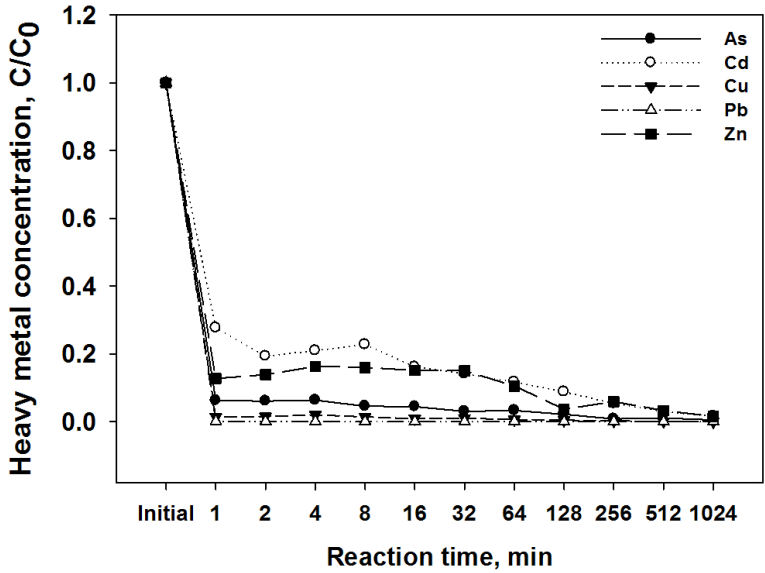

(b) LS:AMDS, 25:75

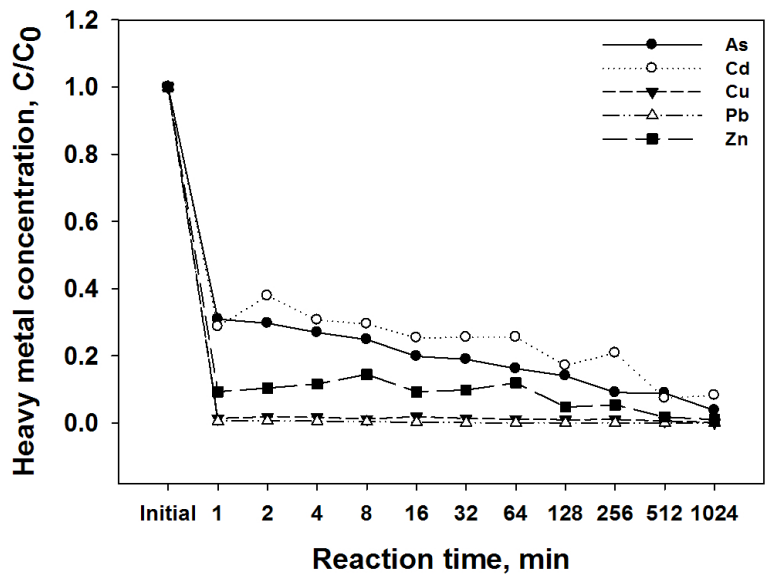

(d) LS:AMDS, 75:25

Fig. 1. Heavy metal concentrations in aqueous solutions after treatment with two different amendments with different mixing ratios at reaction time of 0 to $1024 \mathrm{~min}$. (a $\sim$ e).

된다. 본 연구에서는 반응시간과 안정화제 혼합비율에 따른 중금속 제거효율을 first order kinetic model에 적용하여 반응속도상수와 반감기를 산출한 결과를 Table 3 에 나타내 었다.

$\mathrm{AMD}$ 슬러지만 단일로 처리한 처리구에서는 $\mathrm{As}(\mathrm{k}=1.7062)$ 와 $\mathrm{Pb}(\mathrm{k}=2.8407)$ 에 대하여 큰 반응속도상수를 나타냈으며, 반감기는 각 $0.41,0.24 \mathrm{~min}$.으로 매우 짧게 확인되었다. 또
한 $\mathrm{Cd}, \mathrm{Cu}, \mathrm{Zn}$ 에 대해서도 반감기가 0.71-1.30 $\mathrm{min}$.으로 비교적 짧은 반감기가 확인되었다. 반면, 석회석만 단일로 처리한 처리구에서는 $\mathrm{As}(\mathrm{k}=0.0006)$ 와 $\mathrm{Cd}(\mathrm{k}=0.0004)$ 의 반 감기가 $1155,1732 \mathrm{~min}$.으로 $\mathrm{Cu}, \mathrm{Pb}$ 그리고 $\mathrm{Zn}$ 의 1.53, $0.27,1.30 \mathrm{~min}$. 보다 매우 길게 확인되었다. $\mathrm{Cu}, \mathrm{Pb}$ 및 $\mathrm{Zn}$ 의 반감기는 혼합비율이 달라짐에 따라 큰 차이를 보이지는 않았지만, $\mathrm{As}$ 의 경우 $\mathrm{AMD}$ 슬러지의 혼합 비율이 높아질수 
Table 3. Rate constants (k) and half-life $\left(t_{1 / 2}\right)$ of first order kinetics for different mixing ratios of two amendments.

\begin{tabular}{|c|c|c|c|}
\hline Treatment & Elements & $\begin{array}{c}\text { Rate constants } \\
(\mathrm{k})\end{array}$ & $\begin{array}{l}\text { Half-life time } \\
\left(\mathrm{t}_{1 / 2}, \min .\right)\end{array}$ \\
\hline \multirow{5}{*}{$\begin{array}{c}\text { LS:AMDS } \\
0: 100\end{array}$} & As & 1.7062 & 0.41 \\
\hline & $\mathrm{Cd}$ & 0.6407 & 1.08 \\
\hline & $\mathrm{Cu}$ & 0.9747 & 0.71 \\
\hline & $\mathrm{Pb}$ & 2.8407 & 0.24 \\
\hline & $\mathrm{Zn}$ & 0.5340 & 1.30 \\
\hline \multirow{5}{*}{$\begin{array}{c}\text { LS:AMDS } \\
25: 75\end{array}$} & As & 1.3892 & 0.50 \\
\hline & $\mathrm{Cd}$ & 0.8220 & 0.84 \\
\hline & $\mathrm{Cu}$ & 2.0930 & 0.33 \\
\hline & $\mathrm{Pb}$ & 3.9024 & 0.18 \\
\hline & $\mathrm{Zn}$ & 0.9875 & 0.70 \\
\hline \multirow{5}{*}{$\begin{array}{l}\text { LS:AMDS } \\
50: 50\end{array}$} & As & 1.0781 & 0.64 \\
\hline & $\mathrm{Cd}$ & 0.8950 & 0.77 \\
\hline & $\mathrm{Cu}$ & 2.1142 & 0.33 \\
\hline & $\mathrm{Pb}$ & 3.6818 & 0.19 \\
\hline & $\mathrm{Zn}$ & 1.2684 & 0.55 \\
\hline \multirow{5}{*}{$\begin{array}{c}\text { LS:AMDS } \\
75: 25\end{array}$} & As & 0.6074 & 1.14 \\
\hline & $\mathrm{Cd}$ & 0.4861 & 1.43 \\
\hline & $\mathrm{Cu}$ & 1.9943 & 0.35 \\
\hline & $\mathrm{Pb}$ & 2.5243 & 0.27 \\
\hline & $\mathrm{Zn}$ & 1.1331 & 0.61 \\
\hline \multirow{5}{*}{$\begin{array}{c}\text { LS:AMDS } \\
100: 0\end{array}$} & As & 0.0006 & 1155.00 \\
\hline & $\mathrm{Cd}$ & 0.0004 & 1732.50 \\
\hline & $\mathrm{Cu}$ & 0.4523 & 1.53 \\
\hline & $\mathrm{Pb}$ & 2.5642 & 0.27 \\
\hline & $\mathrm{Zn}$ & 0.5337 & 1.30 \\
\hline
\end{tabular}

록 $1155.00 \mathrm{~min} .>1.14 \mathrm{~min} .>0.64 \mathrm{~min} .>0.50 \mathrm{~min} .>$ $0.41 \mathrm{~min}$.으로 급격히 줄어들었고, $\mathrm{Cd}$ 의 반감기는 석회석: $\mathrm{AMD}$ 슬러지 (LS:AMDS) 50:50의 혼합비율에서 $0.77 \mathrm{~min}$.으로 가장 짧게 확인되었다. 따라서 As 및 중금속에 대한 종합적 인 제거 효율은 석회석과 $\mathrm{AMD}$ 슬러지를 50:50의 비율로 혼 합하는 것이 모든 원소에 대하여 반감기가 $0.8 \mathrm{~min}$. 미만으 로 확인되어 가장 효율적일 것이라 판단된다.

\section{Conclusions}

국민 생활수준의 향상과 먹거리에 대한 인식의 변화로 농산물 및 농경지 환경에 대한 관심이 증대되고 있다. 이에 따라 광산 인근 농경지의 중금속이 큰 이슈가 되고 있으며, 현재 국내에서는 이러한 농경지의 복원방법으로 안정화공 법을 많이 적용하고 있다. 따라서 본 연구에서는 향후 안정 화공법에 적용할 수 있는 안정화제로서 석회석과 $\mathrm{AMD}$ 슬러 지의 최적혼합비율과 그에 따른 중금속 제거 효율성을 수용
액 상에서 평가하였다. 안정화제 내 중금속 함량은 $\mathrm{AMD}$ 슬 러지에서 $\mathrm{Cd}$ 과 $\mathrm{Zn}$ 이 전함량 (aqua-regia) 기준을 초과하는 경향을 보이지만, 실제적으로 토양에 투입되는 비율이나 용 출실험에서는 중금속이 용출되지 않는 점을 고려할 때 적용 가능성이 있을 것으로 판단되며, 또한 용출되는 양보다 중 금속 안정화 능력이 탁월하다면 적용이 가능할 것이라 판단 된다. 석회석과 $\mathrm{AMD}$ 슬러지 혼합에 따른 중금속 제거효율 에서는 석회석이나 $\mathrm{AMD}$ 슬러지의 단일 처리보다는 약 50:50 정도로 혼합하여 처리하는 것이 As 및 중금속 복합 오염군 에 대하여 높은 제거 능력을 보였으며, 반응속도상수와 반 감기면에서도 효과가 좋았다. $\mathrm{AMD}$ 슬러지 단일 처리에 비 하여 석회석을 혼합하여 사용할 경우 석회석의 carbonate $\left(\mathrm{CO}^{3-}\right)$ 및 hydroxide $\left(\mathrm{OH}^{-}\right)$에 의한 $\mathrm{pH}$ 의 교정으로 2 가 양이 온 중금속 $(\mathrm{Cd}, \mathrm{Cu}$ 및 $\mathrm{Zn})$ 의 제거효율이 증가한 것으로 판 단된다. 향후 토양으로의 적용에서도 단일 처리보다 혼합처 리를 한다면 보다 높은 효율을 보일 것으로 판단되지만, 본 연구는 수용액을 이용한 중금속 제거 실험으로 토양적용을 위해서는 여러 가지 토양특성을 고려한 토양 incubation test 또는 현장 시험을 통한 중금속 안정화 효율 시험 추가 적으로 진행되어야 정확할 것으로 사료된다.

\section{References}

Ahn, J.S. 2000. Environmental contamination of arsenic and heavy metals by past Au-Ag mining activities and design of containment system for mine wastes. Doctor Thesis, Seoul National University, Korea.

Ahn, J.S., C.M. Chon, H.S. Moon and K.W. Kim. 2003. Arsenic removal using steel manufacturing byproducts as permeable reactive materials in mine tailing containment Systems, Water Res. 37(10):2478-2488.

An, J.M., H.J. Lee, I.S. Park, K.H. Kim and S.I. Choi. 2010. A Study of Fe removal efficiency of acid mine drainage by physico-chemical treatment, J. Korea Geo-Environ. Soc. 47:550-538.

Cui, Y.J., Y.G. Zhu, R.H. Zhai, D.Y. Chen, Y.Z. Hung and Y. Qui. 2004. Transfer of metals from soil to vegetables in an areas near a smelter in nanning. China Environ. Int. 30(6): 785-791.

Dixit, S. and J.G. Hering, 2003, Comparison of arsenic (V) and arsenic (III) sorption onto iron oxide minerals: implications for arsenic mobility. Environ. Sci. Technol. 37:4182-4189.

Eo, S.M. 1994. Studies on the leaching test in industrial waste. Kor. J. Env. Hlth. Soc. 20(4):72-79.

Fuller, C.C., J.A. Davis and G.A. Waychunas. 1993. Surface chemistry of ferrihydrite: part 2. kinetics of arsenate adsorption and coprecipitation. Geochim. et Cosmochim. Ac. 57:2271-2282. Janos, P., L. Vavrova and V. Pilarova. Herzogova. 2010. Effects of inorganic and organic amendments on the mobility (leacha- 
bility) of heavy metals in contaminated soil: a sequential extraction study. Geoderma. 159:335-341.

Jeon, J.W., B.H. Bae and Y.H. Kim. 2010. Applicability test of various stabilizers for heavy metals contaminated soil from smelter area. J. Kor. Geo-Environ. Soc. 11:63-75.

Jung, T.I., W.C. Lee, H.G. Cho, S.T. Yun and S.O. Kim. 2008. Adsorption of arsenic onto two-line ferrihydrite. J. Miner. Soc. Kor. 21(3):227-237.

Kim M.S., N.I. Koo, J.K. Kim, J.E. Yang, J.S. Lee and G.I. Bak. 2012a. Effects of soil amendments on the early growth and heavy metal accumulation of Brassica campestris ssp. Chinensis Jusl. in heavy metal-contaminated soil. Korean J. Soil Sci. Fert. 45(6):961-967.

Kim, T.H. 2010. Efficiency of chemical remediation technology and stabilization mechanism in heavy metal contaminated soil. Master Thesis. Kangwon National University. Korea.

Kim, J.H., D.Y. Chung, S.J. Oh, R.Y. Kim, J.E. Yang, G,I. Park, J.S. Lee and S.C. Kim. 2012b. Determining soil quality of heavy metal contaminated agricultural field in Korea, Korean J. Soil Sci. Fert. 45(6):1237-1241.

Ko, M.S., J.Y. Kim, S.B. Bang, J.S. Lee, J.I. Ko and K.W. Kim. 2010. An investigation of arsenic stabilization in contaminated soil in the vicinity of abandoned mine using various soil additives. J. Korea Soc. Miner. Energ. Resour. 47(6):834-843.

Kumpiene, J., A. Larerkvist and C. Maurice. 2008. Stabilization of $\mathrm{As}, \mathrm{Cr}, \mathrm{Cu}, \mathrm{Pb}$ and $\mathrm{Zn}$ in soil using amendments - a review. Waste Manage. 28:215-225.

Lee, E.G. 2007. A study on the in-situ stabilization of heavy metals contaminated soils around the abandoned mine area. Master Thesis. Kwangwoon University, Korea.

Lee, J.H., J.Y. Kim, W.R. Go, E.J. Jeong, A. Kunhikrishnan, G.B. Jung, D.H. Kim and W.I. Kim. 2012. Current research trends for heavy metals of agricultural soils and crop uptake in Korea. Korean J. Environ. Agri. 31(1):75-95.

Lim, J.E., K.R. Kim, S.S. Lee, O.K. Kwon, J.E. Yang and Y.S. Ok. 2010. Stabilization of As (arsenic(V) or roxarsone) contaminated soils using zerovalent iron and basic oxygen furnace slag. J. Korea Soc. Environ. Eng. 32(6):631-638.

Maree, J.P., M.J. Hagger, G. Strobos, P. Hlabela, H. Cronje, A. Niekerk, A. Wurster, R. Nengovhela and F.B. Waanders. 2004. Design criteria for limestone neutralization at a nickel mine. Mine Water Environ. 23:152-156.

National Academy of Agricultural Science. 2000. Soil and plant analysis.

Masue, Y., R.H. Loeppert and T.A. Kramer. 2007. Arsenate and arsenite adsorption and desorption behavior on coprecipitated aluminum: Iron hydroxides. Environ. Sci. and Technol. 41:837-842.
Ministry of Environment (ME). 2012. Korean Environment Standard Method.

Ministry of Environment (ME). 2013. Soil Environment Conservation Law.

Moon, D.H., D.Y. Oh, S.j. Lee and J.H. Park. 2010. Stabilization of As contaminated soils using a combination of hydrated lime, Portland cement, $\mathrm{FeCl}_{3} \cdot 6 \mathrm{H}_{2} \mathrm{O}$ and $\mathrm{NaOH}$, Korean J. Environ. Agri. 29(1):47-53.

Moon, D.H., D. Dermates and N. Menounou. 2004. Arsenic immobilization by calcium-arsenic precipitates in lime treated soil. Sci. Total Environ. 330(1-3):171-185.

Moon, D.H., M. Wazne, L-H. Toon, and D.G. Grubb. 2008. Assessment of cement kilnm dust (CKD) for stabilization/ solidification (S/S) of arsenic contaminated soil. J. Hazard. Mater. 159:512-518.

Nan, Z., J. Li, G. Zhang, and G. Cheng. 2002. Cadmium and zinc interaction and their transfer in soil crop system under actual field conditions. Sci. Total Environ. 285:187-195.

Oh, J.I. and S.W. Park. 2005. Settling characteristics of AMD (Acid Mine Drainage) sludge produced by different alkalineutralizer use. Korean Soc. Civil Eng. 25(4B):309-315.

Oh, S.J., S.C. Kim, T.H. Kim, K.H. Yeon, J.S. Lee and J.E. Yang 2011a. Determining kinetic parameters and stabilization efficiency of heavy metals with various chemical amendment. Korean J. Soil Sci. Fert. 44(6):1063-1070.

Oh, S.J., S.C. Kim, H.S. Yoon, H.N. Kim, T.H. Kim, K.H. Yeon, J.S. Lee, S.J. Hong and J.E. Yang. 2011b. Evaluating heavy metal stabilization efficiency of chemical amendment in agricultural field; field experiment. Korean J. Soil Sci. Fert. 44(6):1052-1062.

Raven, K.P., A. Jain and R.H. Loeppert. 1998. Arsenite and arsenate adsorption on ferrihydrite: kinetics, equilibrium, and adsorption envelopes, Environ. Sci. Technol. 32:344-349.

Song, Y.J., G.S. Lee, K.H. Shin, Y.C. Kim, B.W. Seo and S.N. Yoon. 2012. Adsorption of heavy metals on sludge from the treatment process of acid mine drainage. J. Kor. Inst. Resour. Recycling. 21(4):35-43.

Wilkie, J.A. and J.G. Hering. 1996. Adsorption of arsenic onto hydrous ferric oxide: effects of adsorbate/adsorbent ratios and co-occurring solutes. Colloid Surface A. 107:97-110.

Yang, J.E. and K.S. Lee. 2001. Agriculture environment. Kor. Environ. Agri. pp.88-90.

Yang, J.E., D.S. Park and D.S. Han. 1995. Comparative assessment of the half-lives of benfuresate and oxolinic acid estimated from kinetic models under field soil conditions, Korean J. Environ. Agri. 14(3):302-311. 